\title{
The Current Situation, Hot Spot, and Frontier of the Research on the Employment Pressure of College Students in China (Quantitative Visualization Analysis Based on CNKI Core Literature Library in 2002-2019)
}

\author{
$\underline{\text { Zhang Yong }}^{1}$, Luo Renlian $^{2}$, M. Yoserizal Saragih ${ }^{3}$ \\ ${ }^{1}$ School of Resource Environment and Safety Engineering, Hunan University of Science and \\ Technology, XiangTan, China \\ ${ }^{2}$ School of Education, Hunan University of Science and Technology, XiangTan, China \\ ${ }^{3}$ Universitas Islam Negeri Sumatera Utara, Medan, Indonesia \\ Email:292278@qq.com, yosesaragih77@gmail.com
}

\begin{abstract}
In order to understand the development of the research on College Students employment pressure and provide a reference for the research field of College Students' employment pressure, this paper analyzes the current situation, hot spots, and frontier of the research on College Students' employment pressure by using the bibliometric method. The results showed that: the total amount of research on the employment pressure of college students in China showed a significant fluctuation trend; the authors and institutions of the research are distributed in colleges and universities; the research on the employment pressure, social support, mental health education and coping style of college students is the research hotspot and frontier in this field at present.
\end{abstract}

Keywords: college students; bibliometrics; employment pressure; current situation

\section{Introduction}

Bibliometrics method is to grasp the research hotspot and frontier of a subject field through data mining and map analysis, reveal the research evolution characteristics of this field objectively and quantitatively, and avoid the problem of too subjective traditional literature research methods (Zhang Yuanyuan, 2020; Zhang Yuxin, 2020; Yu Yina, 2020). Because of the rich coverage of $\mathrm{CNKI}$, it can provide a solid and comprehensive data support for this study, and this paper chooses CNKI as the data source to study to understand the current research situation of college students' employment pressure.

In this paper, CNKI's journal articles collected in 2002-2019 are taken as the main data. The retrieval conditions are: $(\mathrm{SCI}$ journal $=\mathrm{Y}$ or EI journal $=\mathrm{Y}$ or core journal $=\mathrm{Y}$ or CSSCI journal $=\mathrm{Y}$ or CSCD journal $=\mathrm{Y})$ and between $(1900,2019)$ and $(($ subject $=$ Chinese English extension (College students, Chinese English comparison)) or (title $=$ Chinese English extension (college students, (keywords = Chinese English expansion (employment pressure, Chinese English comparison))) (fuzzy matching), all; database: single database retrieval of academic journals. A total of 86 core journal articles were retrieved. This paper attempts to use the bibliometric and visualization tool of CNKI to draw the scientific knowledge map of the research literature on college students' employment pressure and summarize the current research situation of college students' employment pressure. 


\section{Results and Analysis}

\subsection{Number of Articles Published}

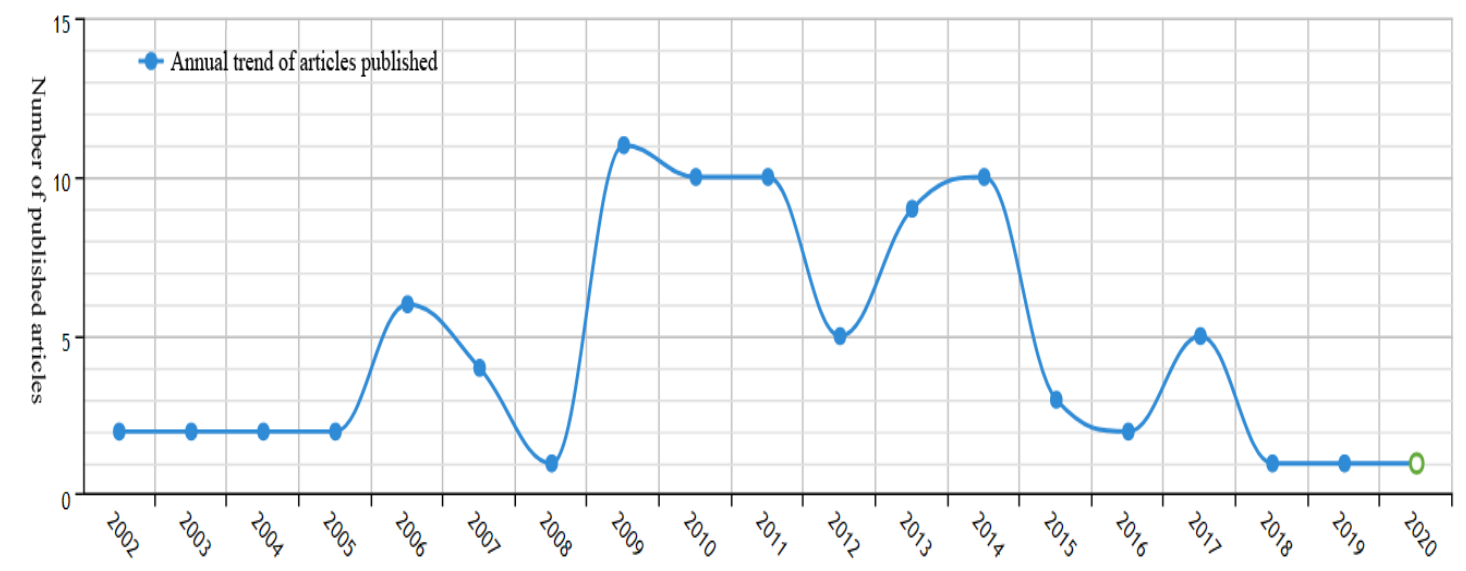

Figure 1. Annual Trend of Articles Published on the Employment Pressure of College Students in 2002-2019

Figure 1 shows that in the past 24 years, the amount of articles published in the study of college students' employment pressure in China has fluctuated dramatically, showing a significant fluctuation. Generally speaking, it can be divided into three stages of development. Although the research on the employment pressure of college students fluctuated from 2002 to 2008 , on the whole, the progress was slow.

The number of articles published from 2009 to 2014 increased significantly, which was a high level. After 2014, it declined sharply. With the transformation of China's higher education from elite to popular, the number of enrollment increases year by year, and the scale of higher education has changed historically, which makes higher education face many new problems and difficulties. At present, the employment mode of "Interview between Supply and Demand, Mutual Selection" for college graduates provides more employment opportunities for graduates and makes graduates' employment more independent. However, graduates' probability of successful employment is closely related to employers' talent demand (Zheng Liqiong, 2009).

The global financial crisis in 2007-2009 has significantly reduced employment opportunities. As a result, the contradiction between the employment position and the number of graduates is continuously expanding. Compared with the past, graduates have to bear more psychological pressure, which may be the main reason for the significant increase in the number of research papers on college students' employment pressure in 2009-2014. China also began to pay more attention to the research and countermeasures of college students' employment pressure. The research field of college students' employment pressure is gradually concerned by more scholars (Gao Feng, 2019; Wang Hua, 2018). 


\subsection{Author Distribution}

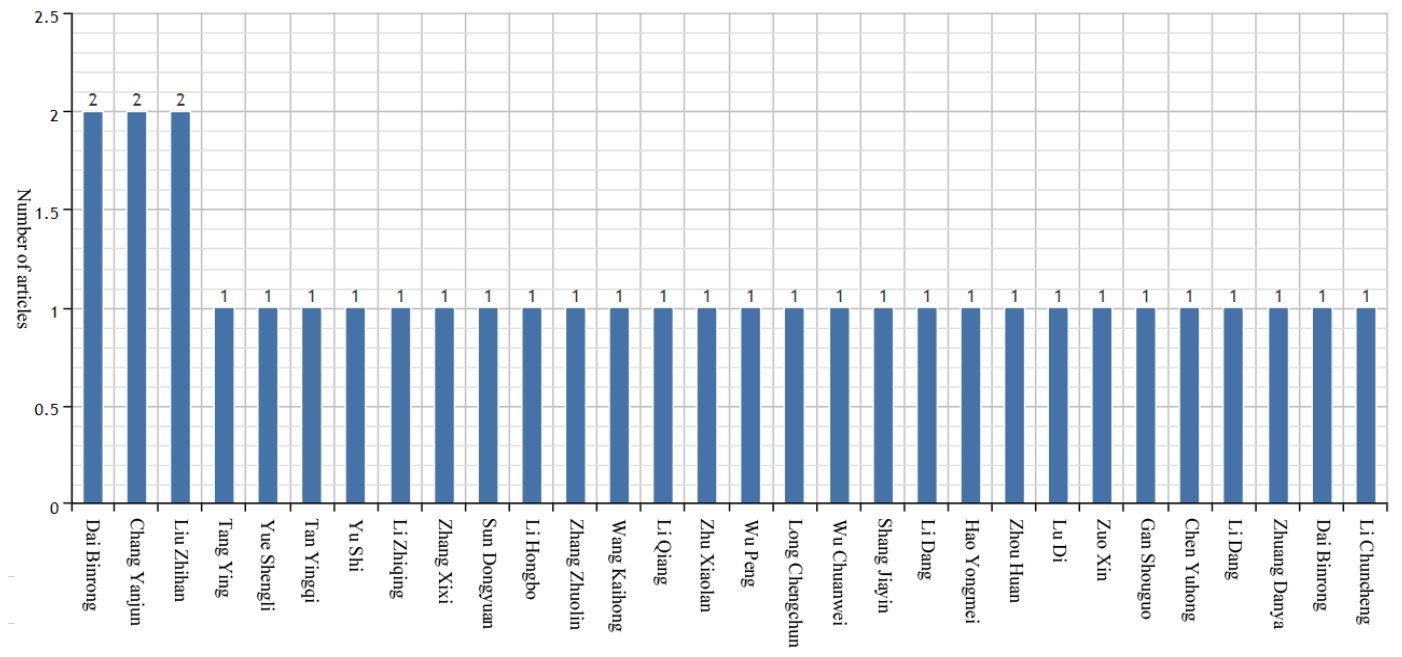

Figure 2. Output Histogram of the Author's Research on the Employment Pressure of College Students in 2002-2019

The number of articles published in core journals is an important indicator to measure an author's academic level and scientific research ability. It can be seen from the top 30 authors of the selected journals that Dai Binrong, Chang Yanjun, and Liu Zhihan have more publications in the field of college students' employment stress research than other authors (Figure 2). However, on the whole, the amount of research on the employment pressure of college students is still meager. On average, the number of papers published by the top 30 authors is 1.1, and the research in this field needs further scholars' further efforts.

\subsection{Distribution of Research Institutions}

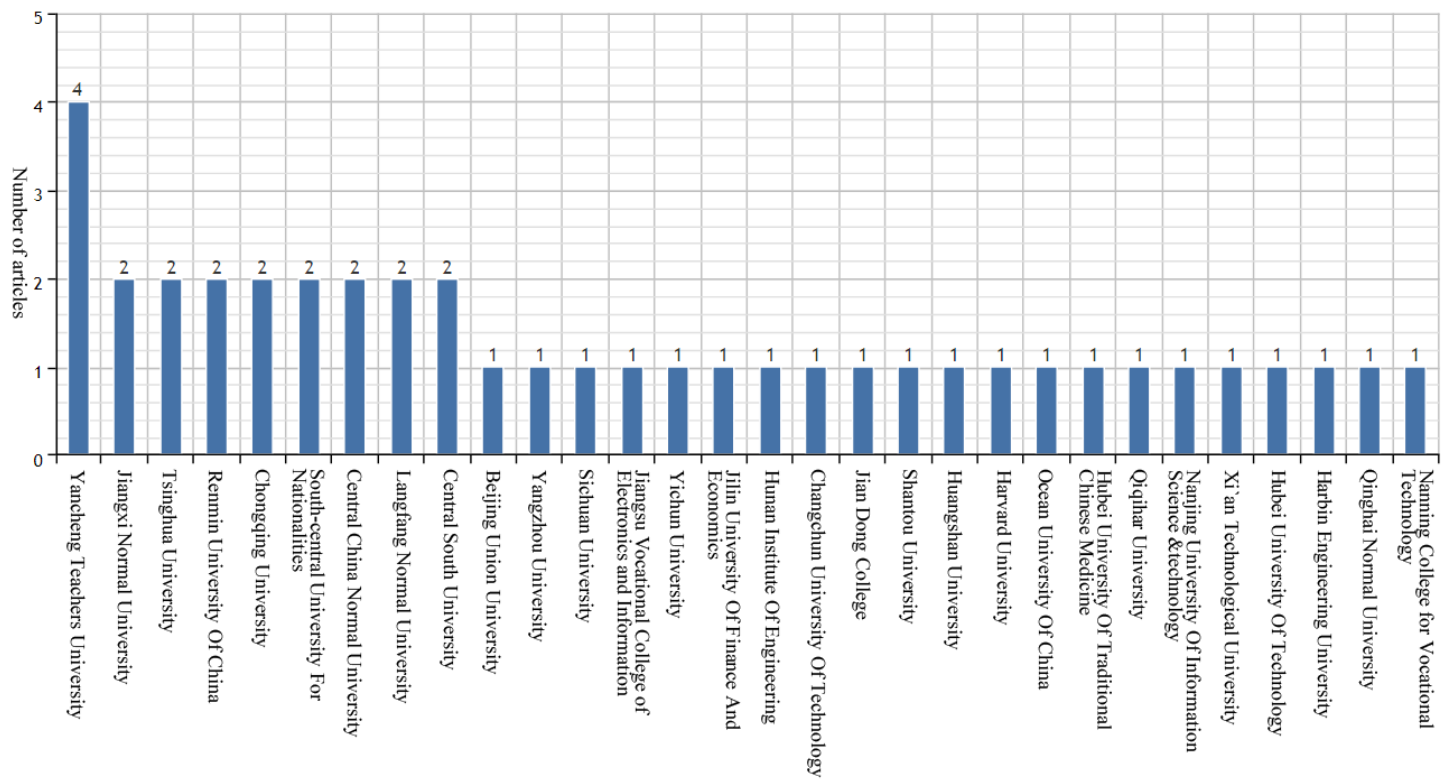

Figure 3. Main Research Institutions of Employment Pressure Research for College Students 
As shown in Figure 3, the leading institutions of employment pressure research of college students in China are distributed at different levels of colleges and universities. The main types of colleges and universities are normal colleges, medical colleges, and vocational and technical colleges.

\subsection{Cited Frequency}

The cited frequency of the article reflects the influence and contribution of the literature. Generally, the higher the cited frequency, the greater the influence. By sorting the cited times of 86 selected articles about college students' employment pressure and analyzing the first five articles, Table 1 is obtained.

Table 1. The Top Five Cited Articles in the Study of Employment Pressure of College Students

\begin{tabular}{|c|c|c|c|}
\hline Ranking & Title & First author & $\begin{array}{c}\text { Cited } \\
\text { frequency }\end{array}$ \\
\hline 1 & $\begin{array}{l}\text { Analysis of the Effects of the Proactive } \\
\text { Personality on Graduates Career Decision- } \\
\text { Making Self- Efficacy }\end{array}$ & Shang Jiayin & 237 \\
\hline 2 & $\begin{array}{l}\text { Study on the function of college students' } \\
\text { entrepreneurship base and the cultivation of } \\
\text { innovative and entrepreneurial talents }\end{array}$ & Sun Xiaomei & 94 \\
\hline 3 & $\begin{array}{l}\text { The Analysis of College Students' Employment } \\
\text { Stressors }\end{array}$ & Li Shengqiang & 80 \\
\hline 4 & $\begin{array}{l}\text { A survey on the types of books and periodicals } \\
\text { helpful to solve the psychological problems of } \\
\text { college students }\end{array}$ & Gong Meiling & 42 \\
\hline 5 & $\begin{array}{l}\text { Research on the Job Hunting Pressure of } \\
\text { Undergraduate Students of BSU }\end{array}$ & Yue Qingli & 37 \\
\hline
\end{tabular}

The most frequently cited is "Analysis of the Effects of the Proactive Personality on Graduates Career Decision-Making Self- Efficacy". This paper uses the revised proactive personality scale to study the effect of proactive personality on college graduates' career decision-making self-efficacy. The results showed that the product of initiative personality and employment pressure has a significant predictive effect on career decision-making self-efficacy and its three subscales (Shang Jiayin, 2009).

A survey of 614 students from five higher vocational colleges by Wei Yu et al. found a significant positive correlation between proactive personality and career choice efficacy, but a significant negative correlation with employment pressure (Wei Yu et al., 2019). Liu Zhihan used the employment pressure scale, social support rating scale, initiative personality scale, and well-being index scale to investigate 490 college graduates. The results also showed that proactive personality negatively predicted employment pressure (Liu Zhihan, 2019); The results of a questionnaire survey of 399 college graduates by Yao Qiong et al. also showed that there was a significant negative correlation between proactive personality and stress factors (Yao Qiong et al., 2012).

The second most cited frequency is "Study on the function of college students' entrepreneurship base and the cultivation of innovative and entrepreneurial talents". This study believes that college students' employment has become a hot issue of broad concern to 
the government, universities, and society in the world financial crisis. It proposes to use the platform advantage of university science and technology park to alleviate the employment pressure of college students by encouraging their entrepreneurship (Sun Xiaomei, 2010). Feni Khairifa et al. explored the relationship between social media use and friendship satisfaction and practice among Universitas Sumatera Utara students. They believe that the more social media platforms are used, the higher the degree of friendship satisfaction among students (Feni Khairifa et al., 2019). Therefore, the good establishment of the corresponding communication platform will make it easier for college students to communicate effectively, effectively alleviating the health problems caused by excessive employment pressure.

The third most frequently cited is "The Analysis of College Students' Employment Stressors". Based on an open-ended questionnaire survey of 741 college students in four universities in Beijing, this study explores the primary sources, types, and characteristics of college students' employment pressure (Li Shengqiang, 2006).

The fourth most frequently cited book is "A survey on the types of books and periodicals helpful to solve the psychological problems of college students". Through the investigation and research of 250 college students in the reading room, the author pointed out that almost any books and periodicals can play a certain role in solving the psychological problems of college students, especially the psychological counseling, life philosophy, novels, leisure books, and periodicals (Gong Meiling et al. 2002).

Chen Hui thinks that domestic colleges and universities do not have enough understanding of music education, and the education methods are generally not scientific and reasonable. Therefore, college students should have great room for improvement in music appreciation and understanding. Therefore, to correctly guide their psychology and relieve the pressure, we can strengthen college students' music education (Chen Hui, 2019). Ju Binjie et al. hold that college students have a series of psychological problems when facing the increasing employment pressure due to the lack of self-debugging ability, unclear self-cognition, and excessive dependence on relatives and friends. Only by multi-party coordination can we get effective results. We should establish and strengthen college students' self-awareness education, establish a long-term psychological counseling mechanism, and improve the employment guidance system (Ju Binjie et al., 2019).

The fifth most frequently cited is "Research on the Job Hunting Pressure of Undergraduate Students of BSU". Based on the questionnaire survey of some graduates of Beijing Sport University, the article showed that college students' employment competitiveness majoring in Physical Education is general, and the employment pressure is high. Therefore, it is necessary to strengthen guidance and targeted employment guidance and services (Yue Qingli et al., 2006). Liang Yanchang's investigation and research on the 2016 Physical Education Major graduates of three universities in Guangzhou University City also showed that this major's undergraduates' employment pressure level was moderate. At the same time, he believes that doing an excellent job in career planning, paying attention to skills and abilities, improving students' practical ability, and carrying out the related courses on employment guidance courses and employment psychological counseling will be of great help to ease the employment press of sports majors' students (Liang Yanchang, 2017). 
According to the investigation results of the employment pressure of college students majoring in Physical Education in Guangxi, Tang Ying et al. proposed a reasonable and effective way to alleviate the employment pressure of college students through providing employment guidance services, formulating personalized career planning, strengthening the cultivation of students' comprehensive quality, and improving their competitive awareness and competitiveness (Tang Ying et al., 2010).

Indeed, other studies, such as "Research on the employment of ethnic minority college students" (Yin Xiaomei, 2009), are frequently cited. The results showed that the continuous expansion of domestic colleges and universities made the graduates of ethnic minority universities face unprecedented employment pressure. The author believes that only taking the road of innovative resettlement with ethnic minority areas' characteristics can solve this difficult situation.

\subsection{Frequency of Subject Words and Keywords}

In this paper, the high-frequency keywords and subject words in the study of college students' employment pressure are analyzed by visual graph analysis and histogram analysis to conduct more intuitive research (Figure 4, figure 5, Figure 6).

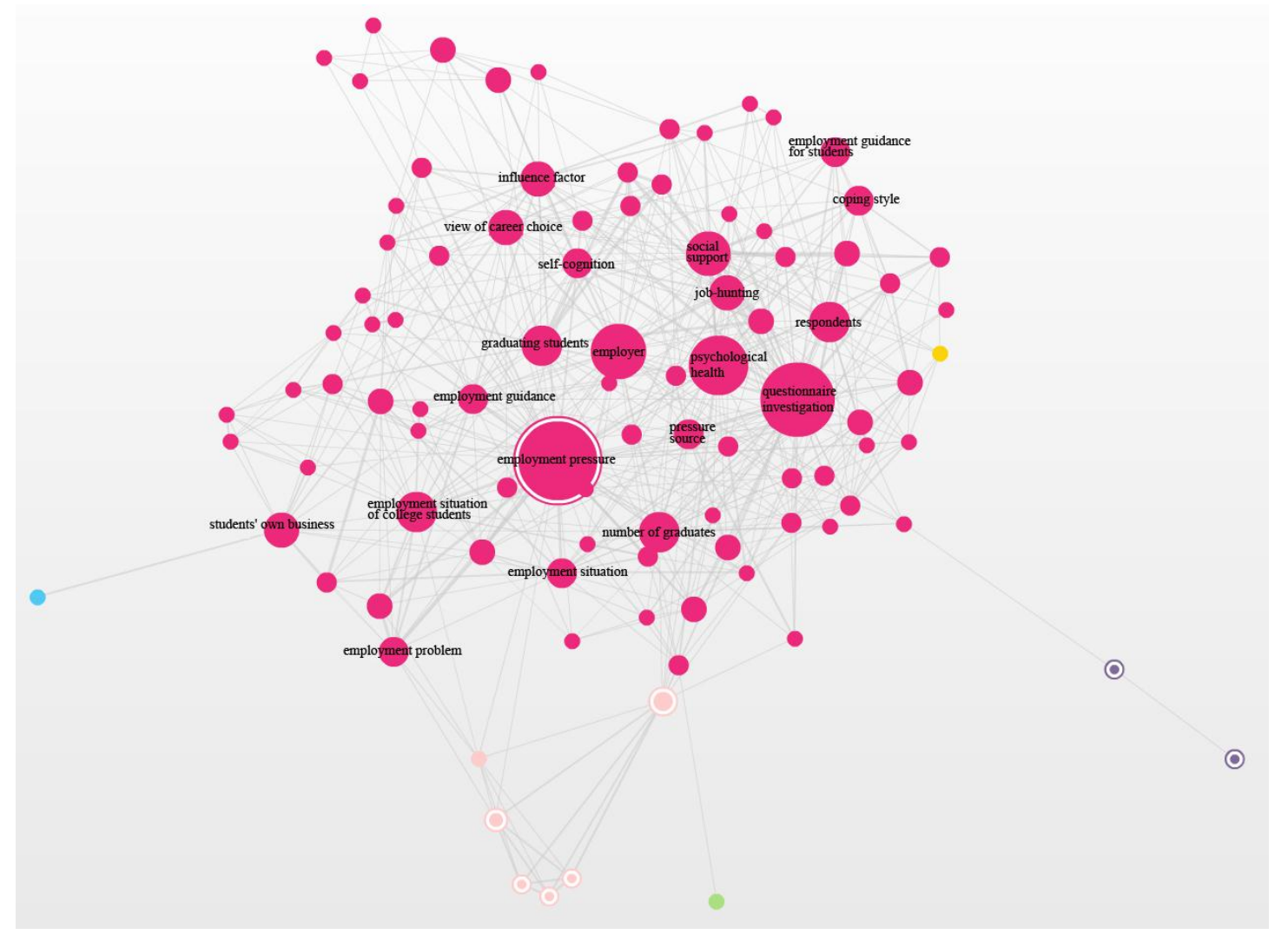

Figure 4. Keywords Map of Employment Pressure Research of College Students

It can be seen from the three figures that, except "employment pressure" and "college students", "social support", "mental health", "coping style", "physical major", and "entrepreneurial intention" are high-frequency words, which are the hot spots of research, indicating that the researches around "social support", "mental health" and "coping style" are the leading hot issues in this research field. 
The study of subjective well-being is an important research field. Li Song's survey of 216 graduates from Xuchang University showed that employment pressure had the most significant impact on college graduates' subjective well-being (Li Song, 2009). The fierce competition for employment has created a huge psychological burden, and the worldwide financial crisis has brought unprecedented challenges.

Based on the unique "Broaden-and-build" function of positive emotions, Liu Zhihan (Liu Zhihan, 2017) proposed a two-way effect between the employment pressure and wellbeing and constructed a conceptual framework to establish a new way to relieve the employment pressure of college students. Sports training may also be an effective means to reduce college students' employment pressure. Nolfie Piri et al. pointed out that physical training can improve physical condition. As a planned sports activity, physical exercise can cultivate physical conditions to better complete the tasks in daily life (Nolfie Piri et al., 2019).

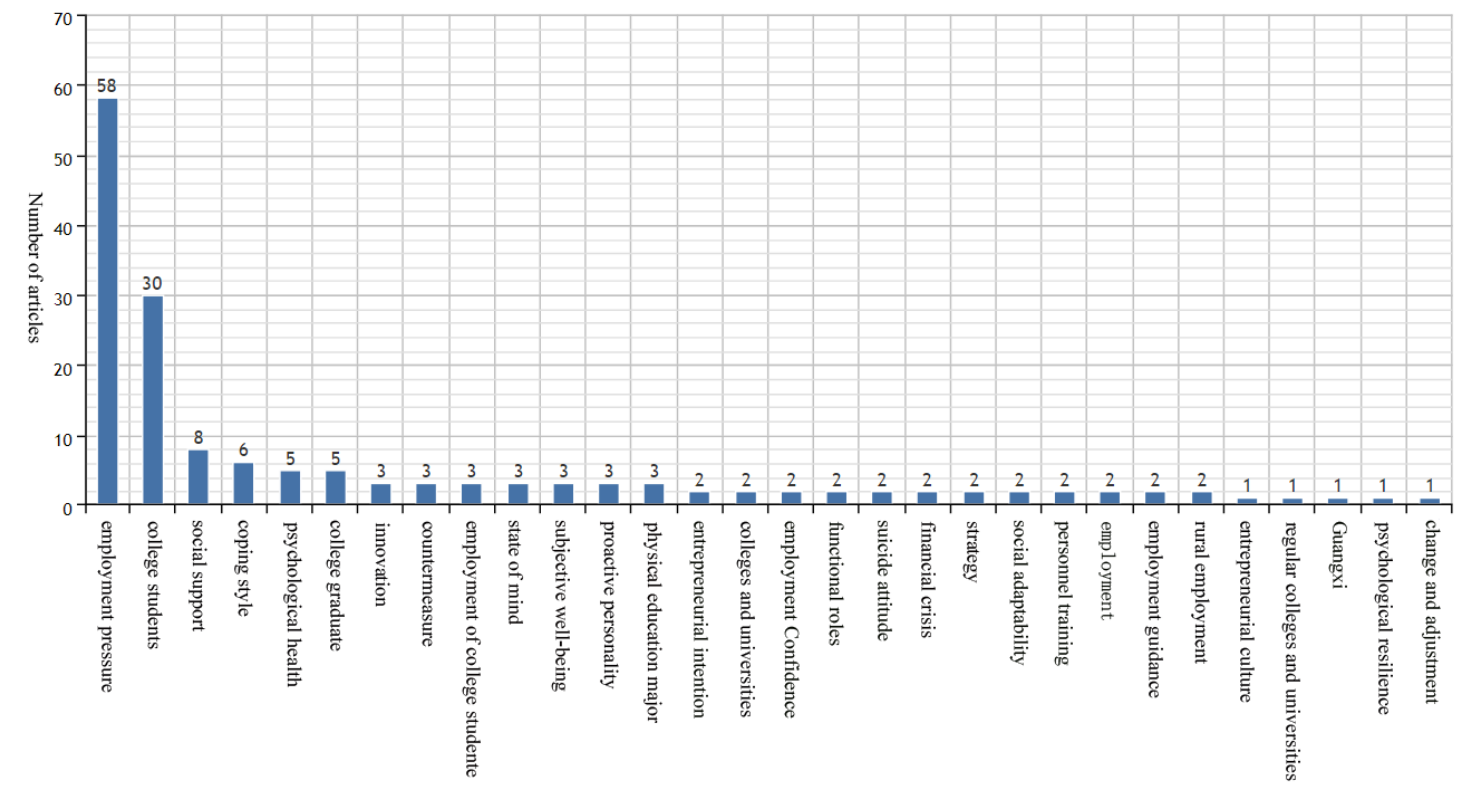

Figure 5. Keywords Distribution of Employment Pressure Research on College Students
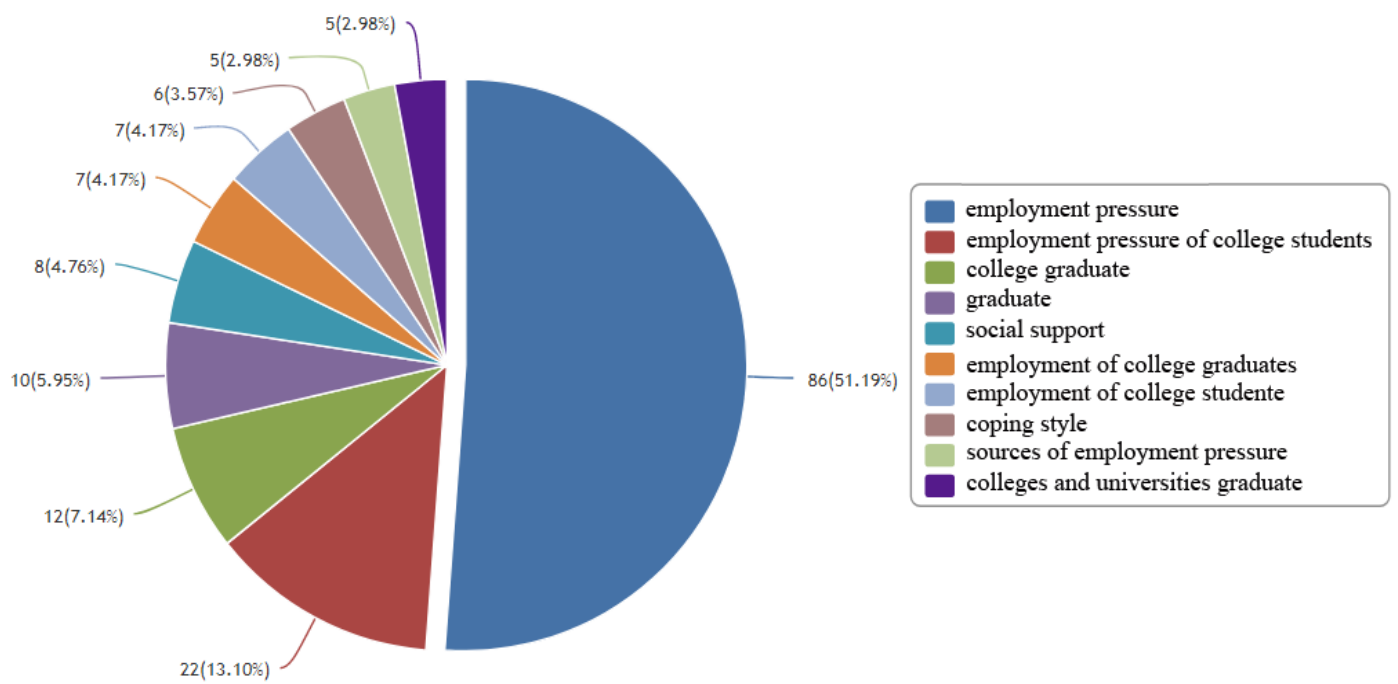

Figure 6. Distribution of Subject Words in the Study of Employment Pressure of College Students 


\section{Conclusion}

Based on the bibliometrics analysis on 86 core articles about college students' employment pressure from 2002 to 2003, this paper finds that many scholars have paid more attention to the research on college students' employment pressure. The research content is closely related to the theme of social development, and the research scope is expanding. Based on the quantitative visualization analysis of CNKI core literature database from 2002 to 2019, the following conclusions can be drawn:

(1) The changes in social economy and education reform are essential factors affecting the employment pressure of college students, and it is also the main reason for the obvious increase in the number of papers published in 2009-2014;

(2) The research on the employment pressure of college students is still weak. The average number of papers published by the top 30 authors is only 1.1 ;

(3) This research is still mainly concentrated in some colleges and universities, and the relevant research in other social institutions is extremely weak.

(4) Only a small number of authors' articles have a high citation rate, which indicates that the research content is too narrow and needs to be expanded;

(5) Overall, the research topics related to college students' employment pressure are relatively extensive, mainly focusing on social support, mental health, coping style, sports major, entrepreneurial intention.

As for the employment pressure of college students, in addition to the attention and help given by the society, schools, and families, the graduates who are about to enter the society should also have a clear, targeted long-term career planning, and use a positive attitude to cope with the increasingly fierce pressure of employment competition.

\section{References}

Gao Feng, Zhang Linlin. 2019. The relationship among employment pressure, self-efficacy and anxiety of college students. Journal of Mudanjiang Normal University (Social Sciences). Number 1. Page 125 - 132.

Chen Hui. 2019. Research on the influence of music education on college students' psychological adjustment function. Northern Music, Volume 39, Number 23. Page 255 $-256$.

Feni Khairifa, Suwardi Lubis, Iskandar Zulkarnain. 2019. The relationship of social media usage to the satisfaction and practice of friendship (Silaturahmi) among students of Universitas Sumatera Utara. Budapest International Research and Critics Institute (BIRCI-Journal): Humanities and Social Sciences. Volume 2, Number 4. Page $575-589$.

Gong Meiling, Congzhong, Wang Lianyun. 2002. A survey on the types of books and periodicals helpful to solve the psychological problems of college students. Chinese Journal of School Health. Volume 23, Number 5. Page 470 - 471.

Ju Binjie, Xia Dan. 2019. Analysis of Current College Students' Employment Psychological Problems and Research on Debugging Strategies. Chinese Geological Education. Volume 28, Number 4. Page $82-84$.

Li Shengqiang, Li Hong, Jin Leili. 2011. The analysis of college students' employment stressors. Tsinghua Journal of Education. Volume 32, Number 2. Page $71-76+82$.

Li Song. 2009. The subjective well-being of college graduates and its influencing factors under the background of the financial crisis. Education and Vocation. Number 21. Page $74-$ 75 . 
Liang Yanchang. 2017. Investigation and analysis of employment pressure of undergraduates majoring in Physical Education in Guangzhou University Town. Science \& Technology Information. Volume 15, Number 4. Page $194-196$.

Liu Zhihan. 2017. A new way to relieve college students' employment pressure: a conceptual framework based on the functional role of subjective well-being. Modern University Education. Number 2. Page 103 - 108.

Liu Zhihan. 2019. Bidirectional mediation effect between job-hunting stress and subjective well-being of college students. Chinese Journal of Clinical Psychology. Volume 27, Number 2. Page 378-382.

Tang Ying, Lü Dongmei, Li Zhiqing, Liang Shaoxiong. 2010. Investigation and analysis of employment pressure against sports major students in Guangxi. Journal of Shanghai University of Sport. Volume 34, Number 2. Page $92-94$.

Nolfie Piri, Ellen Bernadeth Lomboan, Fredrik Alfrets Makadada. 2019. Weight Training Effect of Multi-Poundage System on Bench Press Ability. Britain International of Linguistics, Arts and Education Journal. Volume 1, Number 2. Page 317 - 329.

Shang Jiayin, Gan Yiqun. 2009. Analysis of the effects of the proactive personality on graduates career decision-making self-efficacy. Acta Scientiarum Naturalium Universitatis Pekinensis. Volume 45, Number 3. Page 548 - 554.

Sun Xiaomei. 2010. Study on the function of college students' entrepreneurship base and the cultivation of innovative and entrepreneurial talents. Heilongjiang Researches on Higher Education. Number 1. Page 120 - 122.

Wang Hua, He Lan, Geng Xuan. 2018. Research on the relationship between positive psychological capital and employment pressure of college students. Journal of Jiangsu Ocean University (Humanities \& Social Sciences Edition). Volume 16, Number 6. Page $108-111$.

Wei Yu, Yi Ming. 2019. The relationship among occupational choice self-efficacy, proactive personality and employment pressure of higher vocational students. Journal of Neijiang Normal University. Volume 34, Number 6. Page 14 - 17.

Yao Qiong, Li Hua, Huang Weiming. 2012. Analysis of the influence of proactive personality on college students' career decision-making self-efficacy and employment pressure. Journal of Longdong University. Volume 23, Number 5. Page 85 - 88.

Yin Xiaomei. 2009. Research on the employment of ethnic college students. Heilongjiang National Series. Number 1. Page $184-187+192$.

Yu Yina, Xu Man, Ye Youhua. 2020. A review of forests ecosystem services valuation based on CiteSpace and bibliometric analysis. Ecology and Environmental Sciences. Volume 29, Number 2. Page $421-428$.

Zhang Yuanyuan, Zhang man, Zeng Hao. 2020. The current situation, hot spot, and prospect of political ecology research - bibliometric analysis based on Cite Space. Journal of the Party School of CPC Ningbo Municipal Committee. Number 3. Page 77 - 86.

Zhang Yuxin, Hou Xiyong. 2020. A bibliometric review of the international shoreline changes. Journal of Applied Oceanography. Volume 39, Number 2. Page 289 - 301.

Zheng Liqiong, Li Hongbo. 2009. An analysis of the employment mentality of college graduates. Contemporary Youth Research. Number 11. Page 59 - 62. 